\title{
INFLUÊNCIA DA CONSCIÊNCIA FONOLÓGICA NA AQUISIÇÃO DE LEITURA
}

\section{The influence of phonological awareness in reading acquisition}

\author{
Laura Giotto Cavalheiro ${ }^{(1)}$, Michele Santana dos Santos ${ }^{(2)}$, Poliana Carvalho Martinez ${ }^{(3)}$
}

\begin{abstract}
RESUMO
Objetivo: verificar se a consciência fonológica, principalmente as habilidades em consciência silábica e fonêmica, influencia a velocidade e o nível da leitura. Métodos: participaram deste estudo 60 crianças, de 5 a 8 anos, matriculadas em escolas particulares de Salvador-Bahia que cursavam o $1^{\circ}$ ano do Ensino Fundamental. Foi aplicada a Prova de Consciência Fonológica (PCF), elaborada por Capovilla e Capovilla (1998) para avaliar a consciência fonológica, e textos para avaliar o nível e velocidade de leitura, baseando-se em Capellini e Cavalheiro (2000). Comparou-se e correlacionou-se estatisticamente o desempenho dos escolares na PCF com o nível e a velocidade de leitura. Resultados: foi observado que o nível de leitura está acompanhando o desenvolvimento da consciência fonológica e que a maior pontuação na PCF confere uma maior velocidade de leitura. Conclusão: os resultados indicaram que há uma correlação positiva fraca entre a consciência fonológica e o nível e a velocidade da leitura.
\end{abstract}

DESCRITORES: Leitura; Educação; Desenvolvimento da Linguagem

\section{INTRODUÇÃO}

Consciência fonológica é um tipo de consciência linguística caracterizada pela capacidade que o indivíduo tem de perceber que a fala pode ser segmentada e que seus segmentos (palavras, sílabas e fonemas) podem ser manipulados ${ }^{1}$.

Em crianças pequenas, a consciência de sílabas, rimas e aliterações é muito maior do que a consciência de fonemas, e isso ocorre pois a consciência de segmentos supra fonêmicos (sílabas e palavras) parece desenvolver-se espontaneamente, enquanto que a consciência fonêmica requer experiências específicas além da exposição aos conceitos de rima e aliteração ${ }^{2}$.

Assim como a consciência fonológica, a leitura é uma habilidade metalinguística, porém necessita do conhecimento sobre o uso da linguagem e suas

(1) Fonoaudióloga, mestre em Distúrbios da Comunicação Humana pela Universidade Federal de Santa Maria, Docente do Curso de Fonoaudiologia do Centro Universitário Jorge Amado (UNIJORGE) e União Metropolitana de Educação e Cultura.

(2) Fonoaudióloga graduada pelo Centro Universitário Jorge Amado (UNIJORGE), Salvador/BA.

(3) Fonoaudióloga graduada pelo Centro Universitário Jorge Amado (UNIJORGE), Salvador/BA.

Conflito de interesses: inexistente características formais como a estrutura fonêmica e a sintática ${ }^{3}$. Durante $o$ ato da leitura, a criança deve associar a linguagem oral e a linguagem escrita fazendo a correspondência de cada letra ou grupo de letras com os respectivos fonemas ${ }^{4}$.

Para o desenvolvimento da linguagem escrita é necessária a análise das palavras orais constituídas por elementos fonéticos representados pelo código alfabético, requerendo, assim, capacidades de análise de fala ${ }^{5}$.

Durante a avaliação da leitura, é possível observar habilidades como rotas utilizadas, compreensão, níveis e velocidades na leitura oral e silenciosa. É através desses parâmetros que se pode classificar os bons e os maus leitores ${ }^{6}$.

A leitura é feita de duas formas: utilizando a rota lexical e/ou a rota fonológica. A literatura descreve que o sistema de análise visual identifica o componente visto, ativa o sistema de reconhecimento visual para definir se a palavra é ou não conhecida visualmente e, se esse sistema reconhece o item escrito, ele é processado pela rota lexical, habilidade pertencente a todos os indivíduos. Se a palavra não for reconhecida visualmente, ela é lida através da rota fonológica, que consiste na segmentação da palavra em partes menores (sílabas, letras). Após a conversão de todos os segmentos da palavra, o sistema de síntese fonológica forma 
um todo fonológico que será decodificado pelo sistema de reconhecimento de sons linguísticos. A rota fonológica permite a leitura de palavras novas e pseudopalavras e sua utilização é possível, pois há participação da consciência fonológica na conversão grafema-fonema ${ }^{2}$.

Ainda sobre a leitura, vale considerar que a criança passa por três estágios ou níveis durante 0 desenvolvimento da linguagem escrita ${ }^{7}$ : logográfico, alfabético e ortográfico. No logográfico, a criança lê a palavra como um desenho, considera o contexto, o formato da palavra e faz o reconhecimento visual sem a decodificação alfabética. No estágio alfabético, ocorre a conversão grafo-fonêmica com fortalecimento da relação entre o texto e a fala ${ }^{8}$. Essa fase da leitura subdivide-se em duas: sem compreensão e com compreensão. $\mathrm{Na}$ subfase sem compreensão, acontece a conversão grafema-fonema, porém a criança não entende o significado do que lê; na subdivisão com compreensão ocorre a decodificação fonológica e o acesso ao significado da palavra ${ }^{9}$. No estágio ortográfico, a leitura torna-se madura, acontece a decodificação fonológica e o reconhecimento visual da palavra relacionado ao sistema lexical e à memorização ${ }^{10}$.

A leitura pode ser avaliada de forma silenciosa e oral, sendo necessária nesta última uma codificação fonológica e articulatória, dificultando o acesso direto ao input visual ${ }^{10}$.

A avaliação da velocidade de leitura fornece dados sobre elementos utilizados pelo indivíduo durante $o$ ato para serem analisados, como decodificação dos grafemas, reconhecimento instantâneo, global e parcial, nível de leitura ${ }^{6}$.

Um estudo ${ }^{3}$ sobre velocidade de leitura informa que o input auditivo durante a leitura oral permitiu melhor compreensão do texto ao se comparar com a leitura silenciosa.

Diferentes autores ${ }^{11,12}$ afirmam que a consciência fonológica influencia o processo de aprendizagem da escrita e da leitura, sendo ela preditora de melhores resultados na aquisição da linguagem escrita. Na literatura anglo-saxã e francesa, a consciência fonológica é uma condição para a realização da leitura ${ }^{10}$. Outro autor ${ }^{13}$ afirma que a forte correlação entre consciência fonológica e desempenho em leitura e escrita confirma a relação causal entre essas habilidades, sendo que a leitura e escrita precedem a consciência fonológica. Trabalhos ${ }^{1,14,15}$ relatam que há uma relação de reciprocidade entre o desenvolvimento da consciência fonológica e a aquisição e desenvolvimento da leitura, pois alguns níveis de consciência fonológica interferem no aprendizado da leitura, enquanto que o domínio das habilidades de leitura e escrita possibilita a evolução da consciência fonêmica. As crianças que têm melhor desempenho em consciência fonológica são melhores em leitura e escrita.

Visto que na literatura existem autores que desconsideram a sua antecedência à leitura e à escrita e outros que a julgam como "pré-requisito", para fornecer subsídios para a compreensão do desenvolvimento da linguagem escrita e da consciência fonológica, além de contribuir com o julgamento de condutas terapêuticas, são necessários mais estudos.

Com base no exposto, o objetivo desse trabaIho foi verificar se a consciência fonológica, principalmente as habilidades em consciência silábica e fonêmica, influencia a velocidade e o nível da leitura.

\section{MÉTODOS}

Esta pesquisa consiste em um estudo do tipo quantitativo, transversal e contemporâneo, em que os dados obtidos da amostra no mesmo período de tempo e com uma variedade de características foram associados.

A população do estudo foi composta por 93 crianças de ambos os sexos, que cursavam o $1^{\circ}$ ano do Ensino Fundamental, matriculadas em escolas particulares da cidade de Salvador-Bahia inseridas em uma mesma região, a fim de evitar viés no que se refere ao nível socioeconômico.

Foram excluídas da pesquisa as crianças que eram portadoras de alguma síndrome diagnosticada e alterações visuais, auditivas ou neurológicas previamente conhecidas pelo professor e aquelas que não tiveram o termo de consentimento livre e esclarecido, conforme CNS 196/96, assinado pelos pais ou responsáveis. Esses critérios foram aplicados por meio de entrevista com os professores responsáveis pelas turmas em que eram feitos todos os questionamentos e obtidos os dados pessoais dos alunos.

Não participaram do estudo 33 crianças, sendo uma portadora de Síndrome de Down e 32 que não tiveram o termo de consentimento livre e esclarecido assinado.

A coleta de dados foi realizada em seis escolas particulares de médio porte cujos diretores assinaram termo de compromisso institucional. Apesar de não ter sido feito um estudo estatístico para determinar a significância da amostra, o objetivo inicial da pesquisa foi avaliar 50 crianças, mas como em cada escola visitada nem todos os responsáveis assinaram o termo de consentimento livre e esclarecido e em outras o número de alunos da referida série era restrito, a amostra só foi finalizada após visita à sexta escola. 
Desta forma, a amostra foi constituída de 60 crianças, de ambos os sexos, com idades entre $5 \mathrm{e}$ 8 anos (com média de 6,05 anos).

As avaliações, para a coleta de dados, ocorreram de forma individual, em um único encontro com cada criança de aproximadamente trinta minutos, durante o horário normal das aulas e em locais separados dos demais alunos da classe.

O procedimento utilizado para avaliação da consciência fonológica foi a Prova de Consciência Fonológica (PCF) ${ }^{16}$, que é composta por dez subtestes, relativos a rima, aliteração, segmentação, síntese, manipulação e transposição silábicas e fonêmicas, cada um contendo quatro itens, que foram apresentados de forma oral ao sujeito. Os resultados são apresentados por frequência de acertos, podendo atingir um máximo de 40 pontos, de acordo com o nível de escolaridade, conforme propõe o teste.

Para avaliar a velocidade de leitura, as pesquisadoras basearam-se em Capellini e Cavalheiro ${ }^{3}$ que utilizaram um texto para avaliação da velocidade de leitura oral ${ }^{17} \mathrm{e}$ outro para a velocidade de leitura silenciosa ${ }^{18}$. Este procedimento apresenta textos com similaridade no número total de palavras e uso de palavras regulares e irregulares no seu corpo textual. Foi utilizada, para a análise estatística, somente a velocidade de leitura oral, uma vez que a realização da leitura silenciosa não permite analisar a conversão grafema-fonema e quantificá-la. Não foi encontrada na literatura consultada a padronização da velocidade e níveis de leitura para esta faixa etária, sendo considerada a média do grupo.

Inicialmente, foi aplicada com cada escolar a PCF de forma individual e antes de iniciar a aplicação de qualquer um dos subtestes, foram apresentados dois exemplos iniciais em que as pesquisadoras explicaram a cada criança o que deveria ser feito. Caso a resposta fornecida fosse incorreta, a criança era orientada, nova instrução dada e a aplicação do subteste iniciada. Foram utilizadas fichas de registros nas quais consta o desempenho de cada escolar no teste, bem como acertos e erros.

Após aplicação da PCF, passou-se à avaliação do nível e da velocidade de leitura, solicitando a cada escolar, também de forma individual, que lesse oralmente o texto "As travessuras de Afonsinho" 17 e, após cinco minutos do início (o que era apontado pela pesquisadora), indicasse a palavra que havia sido lida por último para ser feita marcação e análise de quantas palavras a criança havia lido por minuto. Foram feitas perguntas sobre o texto a fim de avaliar o grau de compreensão e, em seguida, solicitado que a criança lesse de forma silenciosa o texto "Os três irmãos" ${ }^{18}$ e o mesmo procedimento foi adotado. Os dados foram anotados em protocolo ${ }^{3}$ para análise.
Para cada texto lido, havia cinco perguntas que eram feitas aos alunos para verificar o nível de compreensão. Uma resposta correta já implicava em presença de compreensão parcial, e a ocorrência de respostas corretas para todas as perguntas significava compreensão total. Tanto a compreensão parcial quanto a total foram consideradas como "presença de compreensão" e a ausência de pelo menos uma resposta correta foi considerada "ausência de compreensão". Esse critério foi utilizado apenas para o nível de leitura alfabético que possui essa subdivisão.

Esse trabalho foi aprovado pela Comissão de Ética para Análise de Projetos de Pesquisa do Centro Universitário Jorge Amado, parecer n 001/2008.

Foi realizada a análise descritiva dos dados em percentuais e utilizado teste de análise estatística com o objetivo de comparar e correlacionar desempenhos. O desempenho apresentado pelos escolares na PCF foi comparado com os valores encontrados em outro estudo ${ }^{16} \mathrm{e}$ analisado estatisticamente por meio do teste t de Student. Foi utilizado o teste de Wilcoxon para comparar e verificar a diferença existente entre as pontuações das habilidades silábicas e fonêmicas. O teste de Kruskal-Wallis foi aplicado para verificar a diferença nas pontuações totais da PCF, das habilidades silábicas e das habilidades fonêmicas ao se comparar com os níveis de leitura, sendo necessário aplicar o método de Holms já que as pontuações diferiram entre pelo menos um par de níveis de leitura. Também foi utilizado o coeficiente de correlação de Spearman para verificar a correlação existente entre a velocidade de leitura oral com a pontuação total da PCF, das habilidades silábicas e das habilidades fonêmicas.

Para classificar a magnitude das correlações estimadas, adotou-se o seguinte critério: coeficiente de correlação $<0,4$ (correlação fraca), $\geq 0,4$ a $<0,5$ (correlação moderada) e $\geq 0,5$ (correlação forte). Estabeleceu-se o nível de significância deste estudo em $5 \%(\alpha=0,05)$.

\section{RESULTADOS}

Os resultados serão apresentados em forma de gráficos e tabelas e posteriormente discutidos.

A maior parte dos escolares apresentou-se no nível de leitura logográfico (45\%) e alfabético sem compreensão (43,3\%), enquanto que o nível alfabético com compreensão corresponde a $11,6 \%$ dos pesquisados e não houve sujeitos no nível de leitura ortográfico.

Observou-se que os escolares apresentaram média de velocidade na leitura oral de 10,09 palavras por minuto, enquanto que a média de velocidade na leitura silenciosa apresentou-se superior, 47,38 palavras por minuto. 


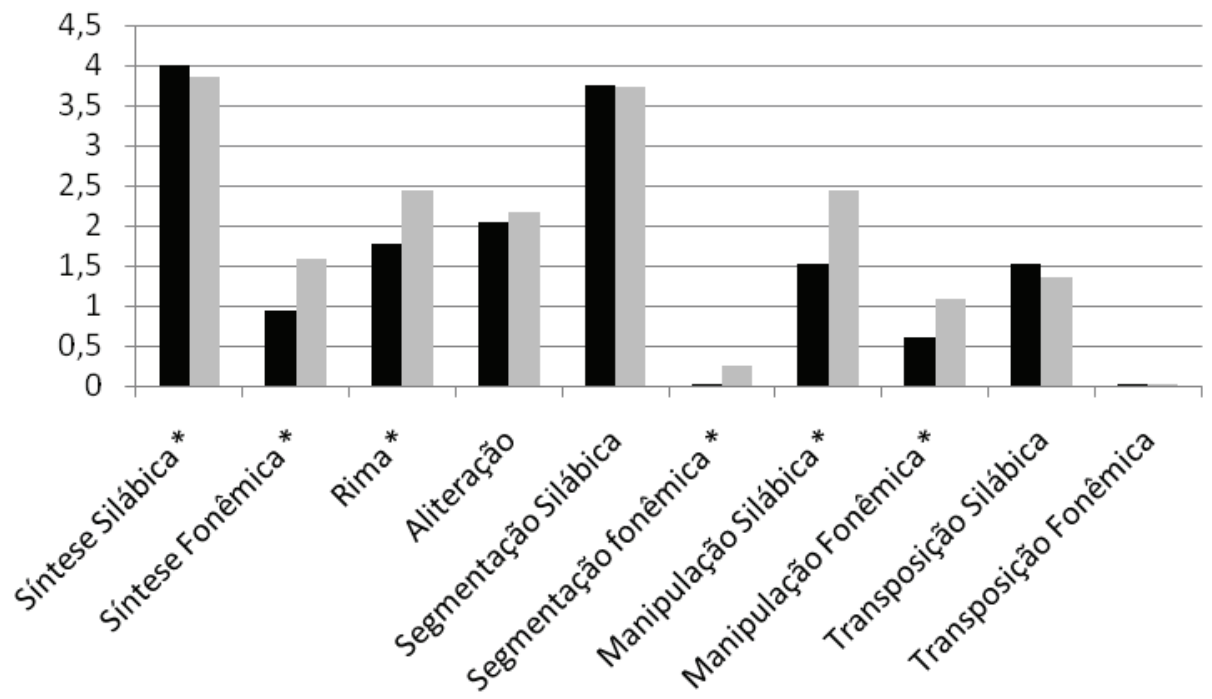

* Habilidades que apresentaram diferença estatisticamente significante

Figura 1 - Gráfico de comparação entre os resultados obtidos e esperados na PCF

Tabela 1 - Média e desvio-padrão das variáveis referentes às habilidades silábicas e fonêmicas

\begin{tabular}{lcccc}
\hline \multirow{2}{*}{ Variáveis } & \multicolumn{2}{c}{ Habilidades } & \multirow{2}{*}{\begin{tabular}{c} 
P-valor \\
\cline { 2 - 3 }
\end{tabular}} & \multicolumn{2}{c}{ Silábicas } & Fonêmicas & (Teste de Wilcoxon) \\
\cline { 2 - 3 } & Média (Desvio-padrão) & Média (Desvio-padrão) & \\
\hline Síntese & $3,97(0,18)$ & $0,93(1,02)$ & $<0,0000^{*}$ \\
Segmentação & $3,73(0,80)$ & $0,03(0,18)$ & $<0,0000^{*}$ \\
Manipulação & $1,52(1,11)$ & $0,62(0,90)$ & $<0,0000^{*}$ \\
Transposição & $1,52(1,81)$ & $0,02(0,13)$ & $<0,0000^{*}$ \\
\hline
\end{tabular}

* Signifcância estatística

Tabela 2 - Média e desvio-padrão da pontuação total PCF, de acordo com os níveis de leitura

\begin{tabular}{|c|c|c|c|c|}
\hline \multirow{3}{*}{ Variáveis } & \multicolumn{3}{|c|}{ Níveis de leitura } & \multirow{3}{*}{$\begin{array}{c}\text { P-valor } \\
\text { (Teste } \\
\text { Kruskal- } \\
\text { Wallis) }\end{array}$} \\
\hline & Logográfico & $\begin{array}{l}\text { Alfabético sem } \\
\text { compreensão }\end{array}$ & $\begin{array}{l}\text { Alfabético com } \\
\text { compreensão }\end{array}$ & \\
\hline & Média (DP) & Média (DP) & Média (DP) & \\
\hline $\begin{array}{l}\text { Pontuação total das } \\
\text { habilidades silábicas }\end{array}$ & $9,26(2,58)$ & $11,46(2,35)$ & $13,71(0,95)$ & $0,0001^{*}$ \\
\hline $\begin{array}{l}\text { Pontuação total das } \\
\text { habilidades fonêmicas }\end{array}$ & $1,30(1,23)$ & $1,58(1,58)$ & $2,86(1,95)$ & 0,1140 \\
\hline Pontuação total PCF & $13,89(4,62)$ & $16,69(4,71)$ & $23,00(3,92)$ & $<0,0003^{\star}$ \\
\hline $\begin{array}{l}\text { Velocidade de Leitura } \\
\text { Oral }\end{array}$ & $5,81(3,00)$ & $10,85(7,38)$ & $23,77(6,17)$ & $<0,0000^{\star}$ \\
\hline
\end{tabular}

DP = Desvio-padrão.

* Significância estatística 
Tabela 3 - Estimativas das correlações entre a velocidade de leitura oral com as habilidades silábicas, fonêmicas e o total da PCF

\begin{tabular}{lcc}
\hline Variáveis & Correlação de Spearman & P-valor \\
\hline Pontuação total das habilidades silábicas & 0,3912 & $0,0020^{*}$ \\
Pontuação total das habilidades fonêmicas & 0,0354 & 0,7883 \\
Pontuação total PCF & 0,3134 & $0,0148^{*}$ \\
\hline
\end{tabular}

* Significância estatística

\section{DISCUSSÃO}

Através da análise dos resultados pôde-se observar que a consciência fonológica está abaixo do esperado para a escolaridade dos sujeitos avaliados ${ }^{16}$, sendo que os aspectos relacionados à consciência fonêmica apresentaram menores escores em relação aos aspectos suprafonêmicos, revelando que há uma hierarquia de aquisição, sendo que o último precede o primeiro ${ }^{2,19-21}$. Isso se deve ao fato de as sílabas serem unidades que requerem menor esforço analítico do que os fonemas, já que são isoláveis na pronúncia ${ }^{2,13}$. Em estudos realizados, foi observado que a habilidade silábica desenvolve-se mais rápido do que a habilidade fonêmica, logo que esta é mais difícil para a criança, justificando assim as achados da presente pesquisa 1,22,23. Além disso, de acordo com um estudo ${ }^{15}$, a consciência fonêmica consolida-se após o aprendizado da linguagem escrita.

Os níveis de leitura apresentados pelos escolares variaram entre o logográfico, alfabético sem compreensão e alfabético com compreensão. Em pesquisa realizada, foi constatado que na $1^{\underline{a}}$ série as crianças utilizam mais o nível logográfico de leitura, sendo o alfabético ainda incipiente ${ }^{24}$, enquanto que outra pesquisa relata que nessa mesma série a leitura logográfica e alfabética já se instalou nos bons leitores, mas não nos maus leitores ${ }^{8}$.

Grande parte dos escolares avaliados encontrase no nível alfabético de leitura, período em que aprendem a realizar conversão grafema-fonema, utilizando predominantemente a rota fonológica para ler, uma vez que apresentam um vocabulário pequeno para realizar o reconhecimento da palavra por input visual ${ }^{25}$. A rota fonológica compreende a habilidade de segmentar, de decodificar grafemas em fonemas e de sintetizar, habilidades estas que compõem a consciência fonológica, o que explica a relação entre elas ${ }^{2,9}$. A utilização da rota fonológica é feita todas as vezes que o indivíduo se depara com palavras não conhecidas visualmente e tem de realizar conversão de segmentos ortográficos em fonológicos, esse procedimento é de extrema importância no início da aquisição de lei- tura e se tornará mais automático à medida que o leitor se torna mais competente ${ }^{2,9,25}$. Crianças em processo de alfabetização ainda não possuem um extenso vocabulário de palavras reconhecidas diretamente, sem mediação fonológica, para utilizarem com mais frequência a rota lexical. Dessa forma, nesse período, o uso da rota fonológica é imprescindível para a expansão do léxico ortográfico da criança ${ }^{25,26 .}$

Foi verificado que a média da velocidade de leitura oral foi menor do que a média da velocidade de leitura silenciosa, o que vai ao encontro aos achados de Capellini e Cavalheiro ${ }^{3}$. Isso pode ser justificado pelo fato de os escolares avaliados neste estudo ainda se encontrarem em processo de desenvolvimento da conversão grafema-fonema e, como a leitura silenciosa não possibilita o monitoramento auditivo da leitura, muitas das crianças avaliadas podem estar evitando auto-correções ou realizando leitura de palavras de maior complexidade por adivinhações, não apresentando desempenho real para a conversão grafema-fonema.

Observa-se que a velocidade de leitura oral apresenta-se baixa para todos os escolares, o que corrobora estudo realizado que afirma que crianças de séries iniciais tendem a ler de forma mais lenta, uma vez que o processamento se dá pela rota fonológica. À medida que a escolaridade aumenta, a velocidade de leitura também, já que o número de palavras armazenadas no seu léxico visual é maior ${ }^{27}$.

Os resultados dessa pesquisa diferem dos encontrados em estudo realizado em uma população de hiperléxicos ${ }^{28}$, os quais revelaram que, quanto menor a velocidade de leitura oral, maior foi a compreensão do texto lido. Isso se dá pelo fato de na hiperlexia haver falha na rota fonológica, inabilidade na conversão grafema-fonema e acesso ao significado, enquanto que na amostra deste estudo, os sujeitos que apresentaram nível de leitura alfabético com compreensão foram os que apresentaram maior velocidade, uma vez que essa é uma etapa natural de aquisição da leitura, em que quanto mais rápida a conversão grafema-fonema, melhor a compreensão. 
As crianças com o nível de leitura logográfico foram as que apresentaram piores desempenhos na Prova de Consciência Fonológica com algumas exceções; as que apresentaram o nível de leitura alfabético sem compreensão oscilaram na pontuação da PCF e as que apresentaram o alfabético com compreensão como nível de leitura obtiveram melhor pontuação. Os resultados encontrados entram em concordância com outros estudos 21,29,30 que afirmam que a presença da consciência fonológica permite melhor desenvolvimento e desempenho em leitura. Em estudo realizado ${ }^{31}$, verificou-se que a terapia em consciência fonológica facilitou o aprendizado da leitura, o que evidencia uma influência positiva da primeira na segunda.

Uma vez que a habilidade fonêmica ainda não se desenvolveu nos escolares, o que está de acordo com o desempenho encontrado em outro estudo ${ }^{16}$ para o nível de escolaridade, observou-se, neste estudo, uma ausência de correlação significante entre ela e os níveis e velocidade de leitura. A partir desse achado, pode-se sugerir que a exposição ao sistema alfabético auxilia no desenvolvimento da consciência fonológica, principalmente a nível fonêmico 1,15,32. Com base em estudos desenvolvidos $^{2,29}$, pode-se inferir que há uma relação direta entre a consciência fonêmica e o nível e velocidade de leitura, uma vez que, após treino para desenvolver a consciência fonológica, houve ganho nas habilidades citadas.

Os sujeitos avaliados encontram-se em processo de aquisição de leitura e possuem poucas palavras no seu léxico visual, usam preferencialmente a rota fonológica e esta ainda de maneira deficitária, o que pode estar determinando lentidão na velocidade de leitura oral. Diante dessa problemática, infere-se que o fato de a rota fonológica estar intrinsecamente ligada à consciência fonêmica e esta não estar plenamente desenvolvida, ocorre um aumento no tempo da conversão grafema-fonema e, consequentemente, diminuição da velocidade de leitura. Tais achados corroboram outro estudo ${ }^{33} \mathrm{em}$ que a consciência fonológica, mais especificamente a consciência fonêmica, está relacionada à velocidade de leitura.

Os achados dessa pesquisa comprovam a existência de uma correlação entre as habilidades em consciência fonológica e a velocidade e o nível de leitura ${ }^{26,30,32}$. As crianças que apresentaram maior habilidade na manipulação dos sons da fala conseguiram desenvolver velocidade e nível de leitura de maneira mais eficiente. Em trabalho publicado ${ }^{11}$, esse aspecto ficou evidenciado, pois a consciência fonológica foi a habilidade que mais apresentou influência no desenvolvimento da linguagem escrita, desempenhando um papel facilitador, de forma a permitir que a leitura se desenvolvesse de maneira potencializada nas crianças com melhores índices de consciência fonológica.

Outro estudo ${ }^{12}$ refere que na consciência fonológica a habilidade fonêmica influencia mais no desempenho da leitura e escrita do que a habilidade silábica, o que corrobora os achados dessa pesquisa em que o maior escore de erros foi no nível fonêmico da consciência fonológica. O raciocínio dos autores foi comprovado na pesquisa, pois a maior porcentagem dos escolares apresentou nível logográfico de leitura oral.

\section{CONCLUSÃO}

Os resultados obtidos neste estudo indicaram que existe correlação positiva fraca significante entre a consciência fonológica, principalmente as habilidades em consciência silábica e fonêmica, e o desenvolvimento da velocidade e do nível de leitura.

\section{ABSTRACT}

Purpose: To check if the phonological awareness, mostly the skills of syllabic and phonetic awareness, has influence on reading speed and level. Methods: sixty children took part in this study, between 5 and 8-year old, first grade students at private schools of Salvador, Bahia. We applied the Phonological Awareness Test (PAT), developed by Capovilla and Capovilla (1998) in order to assess the phonological awareness, and also texts in order to assess reading level and speed, which was based on Capellini and Cavalheiro000). We compared and correlated statistically the performance of the students in the Phonological Awareness Test as for reading level and reading speed. Results: We observed that the reading level is following the development of phonological awareness and that the highest score in the PAT provides for a greater speed reading. Conclusion: the results indi (2cate that there is a weak positive correlation among the phonological awareness and reading level and speed.

KEYWORDS: Reading; Education; Language Development 


\section{REFERÊNCIAS}

1. Pestun MSV. Consciência fonológica no início da escolarização e o desempenho ulterior em leitura e escrita: estudo correlacional. Estud. Psicol. 2005; 10(3):404-12.

2. Capovilla AGS, Capovilla FC. Problemas de Leitura e Escrita: como identificar, prevenir e remediar numa abordagem fônica. 3. ed. São Paulo: Memnom; 2000.

3. Capellini AS, Cavalheiro LG. Avaliação do nível e da velocidade de leitura em escolares com e sem dificuldade na leitura. Temas Desenvolv. 2000; 9(51):5-12.

4. Plaza M, Normand MT, Siegel LS. Distúrbios específicos de aprendizagem da leitura. As dislexias. In: Muller-Chevrie C, Narbona J, Wolff $\mathrm{J}$. A linguagem da criança: aspectos normais e patológicos. 2. ed. Porto Alegre: Artmed; 2005. p. 382-402.

5. Silva AC. Consciência fonológica e aprendizagem da leitura: Mais uma versão da velha questão da galinha e do ovo. Análise Psicol. 1997; 2(15):283-303.

6. Grégorie J. O diagnóstico dos distúrbios de aquisição da leitura. In: Grégorie J, Piérart B. Avaliação dos problemas de leitura, os novos modelos teóricos e sua implicação. Porto Alegre: Artes Médicas; 1997. p. 35-64.

7. Frith $U$. Beneath the surface of developmental dyslexia. In: Patterson K, Marshall J, Colthert M. Surface dyslexia: neuropsychological and cognitive analyses of phonological reading. London: Lawrence Erlbaum Associates; 1985. p. 56-87.

8. Capovilla AGS, Joly MCRA, Ferracini F, Caparrotti NB, Carvalho MR, Raad AJ. Estratégias de leitura e desempenho em escrita no início da alfabetização. Psicol Esc Educ. 2004; 8(2):189-97.

9. Capovilla FC, Macedo EC, Charin S. Competência de leitura: tecnologia e modelos de compreensão em leitura silenciosa e de reconhecimento e decodificação em leitura em voz alta. In: Navas ALGP, Santos MTM. Distúrbios de Leitura e Escrita: Teoria e Prática. Barueri (SP): Manole; 2004. p. 97-160.

10. Muller-Chevrie C, Soprano A-M. Avaliação das aprendizagens escolares: leitura, ortografia, matemática. In: Muller-Chevrie C, Narbona J, Wolff $J$. A linguagem da criança - Aspectos normais e patológicos. 2. ed. Porto Alegre: Artmed; 2005. p. 183-207.

11. Barrera SD, Maluf MR. Consciência metalinguística e alfabetização: um estudo com crianças da primeira série do ensino fundamental. Psicol Reflex Crit. 2003; 16(3):491-502.
12. Capovilla AGS, Gutschow CRD, Capovilla FC. Habilidades cognitivas que predizem competência de leitura e escrita. Psicol Teor Prat. 2004; 6(2):13-26.

13. Pestun MSV. Investigação precoce da consciência fonológica e futura habilidade de leitura e escrita. Temas Desenvolv. 2004; 13(73):5-12.

14. Guimarães SRK. Dificuldades no desenvolvimento da lectoescrita: o papel das habilidades metalinguísticas. Psic Teor Pesq. 2003; 19(1):33-45.

15. Romero PG, Mota HB, Keske-Soares M. A terapia em consciência fonológica no processo de alfabetização. Pró-Fono. 2005; 17(2):175-84.

16. Capovilla AGS, Capovilla FC. Prova de consciência fonológica: desenvolvimento de dez habilidades da pré-escola à segunda série. Temas Desenvolv. 1998; 7(37):14-20.

17. Rocha R. As aventuras de Afonsinho. São Paulo: Ática; 1980.

18. Grim I. Os três irmãos. In: Condemarin $M$, Blomquist M. Dislexia: manual de leitura corretiva. Porto Alegre: Artes Médicas; 1989. p. 52-3.

19. Gindri G, Keske-Soares M, Mota HB. Memória de trabalho, consciência fonológica e hipótese de escrita. Pró-Fono. 2007; 19(3):313-22.

20. Bernardino Júnior JA, Freitas FR, Souza DG, Maranhe EA, Bandini HHM. Reading and writing acquisition as a result of teaching phonological awareness abilities. Rev. Bras. Educ. Espec. 2006; 12(3):423-50.

21. Barrera SD, Maluf MR. Consciência fonológica e linguagem escrita em pré-escolares. Psicol Reflex Crit. 1997; 10(1):125-45.

22. Cavalcante CA, Mendes MAM. A avaliação da consciência fonológica em crianças de primeira série alfabetizadas com metodologias diferentes. Rev. CEFAC. 2003; 5 (3) :205- 8.

23. Germano GD, Pinheiro FH, Capellini SA. Desempenho de escolares com dislexia do desenvolvimento em tarefas fonológicas e silábicas. Rev. CEFAC. 2009; 11(2):213-20.

24. Capovilla AGS, Dias NM. Desenvolvimento de estratégias de leitura no ensino fundamental e correlação com nota escolar. Psicol Rev. 2007; 13(2):363-82.

25. Salles JF, Parente MAMP. Cognitive processes involved in children's word reading: relations with reading comprehension and reading time. Psicol Reflex Crit. 2002; 15(2):321-31.

26. Capellini SA, Conrado TLBC. Desempenho de escolares com e sem dificuldades de aprendizagem de ensino particular em habilidade fonológica, nomeação rápida, leitura e escrita. Rev. CEFAC. 2009; 11(2):183-93. 
27. Macedo EC, Capovilla FC, Nikaedo CC, Orsati FT, Lukasova K, Capovilla AGS et al. Teleavaliação da habilidade de leitura no ensino fundamental. Psicol Esc Educ. 2005; 9(1):127-34.

28. Silva RCD. Hiperléxicos com transtorno de Asperger: caracterização da leitura e escrita de textos e palavras [dissertação]. São Paulo: Universidade Federal de São Paulo. Escola Paulista de Medicina; 2004.

29. Salgado CA, Capellini SA. Programa de remediação fonológica em escolares com dislexia do desenvolvimento. Pró-Fono. 2008; 20(1):31-6.

30. Dambrowski AB, Martins CL, Theodoro JL, Gomes E. Influência da consciência fonológica na escrita de pré-escolares. Rev. CEFAC. 2008; 10(2):175-81.
31. Paula GR, Bolli Mota H, Keske-Soares H. A terapia em consciência fonológica no processo de alfabetização. Pró-Fono. 2005; 17(2):175- 84.

32. Britto DBO, Castro CD, Gouvêa FG, Silveira OS. A importância da consciência fonológica no processo de aquisição e desenvolvimento da linguagem escrita. Rev Soc Bras Fonoaudiol. 2006; 11(3):142-50.

33. Capellini AS, Mousinho R, Mesquita FS, Calmon N, Leal J, Saviolo J, et al. Correlação entre compreensão, fluência, velocidade e precisão de leitura e relação com habilidades metalinguísticas e cognitivas. XVI Congresso Brasileiro de Fonoaudiologia. 24 a 27 de setembro 2008; Campos do Jordão. p. 1158-61.

DOI: 10.1590/S1516-18462010005000063

RECEBIDO EM: 11/11/2009

APROVADO EM: 06/04/2010

Endereco para correspondência:

Laura Giotto Cavalheiro

Alameda Praia de Guaratuba, 1575, casa 11, Stela Mares

Salvador - Bahia

CEP: 41600-270

E-mail laufono@uol.com.br 